\title{
Marmoset colony set to grow in Texas
}

\author{
Ellen P. Neff
}

$$
\text { E: }
$$
verything is bigger in Texas, the saying goes. That includes the soon-to-be expanded marmoset colony at the Texas Biomedical Research Institute (Texas Biomed), a nonprofit research institution in San Antonio. In an agreement announced in April, a cohort of about 100 marmosets currently residing at The University of Texas Health Science Center at San Antonio (UT Health) as part of an aging colony there will join about 340 other marmosets in a single facility maintained at the Southwest National Primate Center (SNPRC), part of Texas Biomed.

In total, up to 550 Callithrix jacchus marmosets, small New World monkeys native to the rainforests of Brazil, might one day call San Antonio home. That could include 90 to 175 geriatric animals for aging research conducted in continued collaboration with UT Health as well as a few hundred more for a variety of other research purposes, including as models for the development of potential Department of Defense-funded Zika vaccine.

The facility at Texas Biomed has been expanding and renovating to accommodate more marmosets. A building that previously housed rodents as well as marmosets will soon be dedicated solely to the nonhuman primates, including a specially designed, positive airflow geriatric wing for the aged animals. The facility has also been hiring more care staff and preparing them for the influx of new charges.

The expansion comes as interest in the precocious nonhuman primates continues to grow rapidly - to the point where demand for marmosets is outpacing the available supply of animals in the United States. According to a recent NASEM ILAR Report, there are about 1900 marmosets living across 27 research colonies in the US. The SNPRC is one of just two large NIH-funded national primate centers that raise the animals - the other, the Wisconsin National Primate Research Center at the University of Wisconsin-Madison, currently has about 250 individuals. Several private, USDAapproved vendors breed marmosets, but supply is still strained. "The queue right now for marmoset projects is about three years," says Corinna Ross, associate professor and marmoset colony administrator at Texas Biomed. "Hopefully, we can increase what we can supply."

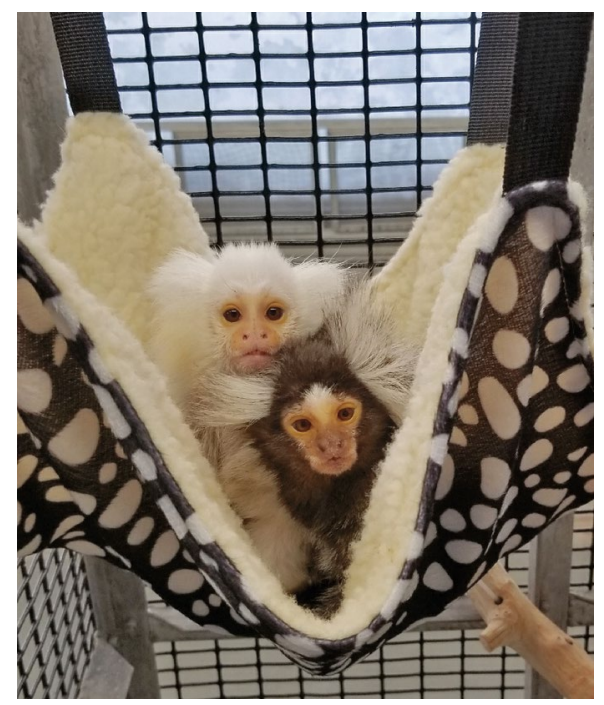

Marmosets, Callithrix jacchus, hunkering down in a hammock. Credit: Texas Biomedical Research Institute

The marmosets have a number of advantages in biomedical research, Ross says. As nonhuman primates, they share a closer evolutionary history and anatomical and physiological features to humans than other mammalian model organisms, such as the rodent. But they're a bit more rodent-sized than other primates. Adult macaques can weigh in between five and seven kilograms; a marmoset tips the scales at about 350 grams, about the size of a rat. They should not, however, be mistaken for a rodent.

"The thing that we talked about most with new investigators is that they're different," says Ross. "They're not just big rodents, and so you can't use things that you use for rodents and just expect the marmoset to respond." Nor are they just little macaques. "They have different little reactivities and quirks," she says, that those new to working with them must become accustomed to. With Old World monkeys such as macaques, for example, eye contact is best avoided because the animals interpret that as a sign of aggression; marmosets look for it in the people around them. "If you don't look them in the eye, they become very concerned," says Ross.

Though they take up less space than a macaque or other larger primate, they demand attention. "They are fussy little things," says Ross. They can be hyper-reactive to the unfamiliar, so new staff must be introduced slowly. Pseudo-monogamous in the wild, they do best kept in families or paired cages and they benefit from lots of enrichment-both cognitive and physical. For a gummivorous animal with a notable sweet tooth-marshmallows are common forms of motivation, says Ross-obesity has become a growing concern among marmoset colonies. That could be an advantage for their use as a biomedical model of metabolic diseases she says, "but from a marmoset perspective, we don't know why that's happening. We don't know if it's simply that they're not working for their food-sort like how we don't work for food....or if there's something else about being bred in captivity for generations that they're now trending towards obesity."

The attention they are getting as model organisms-from aging and neuroscience to social behavior and communication to immunology \& vaccines-is thus welcome. "I'm glad that people are interested them," says Ross, who herself has worked with the animals since her graduate school days at the University of Nebraska. "That means we can learn more about them just in general, not just as a biomedical model." Research is not only about increasing health and wellbeing for humans, she says, but also about translating what's learned about the animals into benefits for them too. For example, adapting cognitive tests to suit a marmoset, rather than a rodent or a macaque, is needed for neuroscience research, but such tasks could prove beneficial for animal welfare too. "Modifying those [tests] has been challenging," she says, "We're interested in doing that not just because we're interested in cognitive science but again, it's another way of possibly enriching what they're doing during the day and getting them to work."

Moving day for the marmosets in Texas is still to be determined-Texas Biomed is taking things slowly to make sure staff is prepared and the animals aren't subject to any undue stress, Ross says-but the aging animals are expected to be en route across San Antonio to their new home later this summer.

\section{Ellen P. Neff \\ Lab Animal. \\ e-mail:ellen.neff@us.nature.com}

Published online: 6 August 2019 https://doi.org/10.1038/s41684-019-0378-7 